\title{
LÍNGUAS, LIVROS E LEIS: O APAGAMENTO DA CULTURA INDÍGENA E RESISTÊNCIA
}

\author{
Andrea Cristiane Kahmann ${ }^{1}$ \\ Universidade Federal de Pelotas (UFPEL) \\ Marcia Rodrigues Bertoldi ${ }^{2}$ \\ Universidade Federal de Pelotas (UFPEL) \\ Isabela Figueroa $^{3}$ \\ Universidad del Magdalena (UNIMAGDALENA) \\ Ana Carla Oliveira Bringuente ${ }^{4}$ \\ Faculdade Dom Alberto (FDA)
}

\section{RESUMO}

O trabalho propõe uma revisão sobre a formação do Estado brasileiro desde a perspectiva do colonialismo e da colonialidade, orientada pela teoria da decolonialidade, partindo da história das línguas e dos livros em direção à lei e ao apagamento das culturas indígenas. As peculiaridades da colonização brasileira, suas diferenças frente aos países vizinhos latino-americanos e os ecos deste processo no Brasil contemporâneo perpassam os quatro pontos em que se estrutura este trabalho, a saber: (1) a diversidade linguística do Brasil originário e nas mudanças decorrentes do processo de conquista europeu; (2) o processo de independência (política,

1 Doutora e mestre em Letras pela Universidade Federal do Rio Grande do Sul (UFRGS). Especialista em Gestão Estratégica Municipal pela Universidade de Santa Cruz do Sul (UNISC). Graduada em Letras pela UNISC. Graduada em Direito pela UNISC. Coordenadora do Curso de Bacharelado em Letras - Tradução Espanhol/Português da UFPEL. ORCID: http://orcid.org/0000-0001-8582-9210 / e-mail: ackahmann@gmail.com

2 Doutora em Globalização e Direito pela Universidad de Girona UDG, revalidado pela Universidade Federal de Santa Catarina (UFSC). Doutora em Estudos Internacionais pela Universidad Pompeu Fabra (UPF). Graduada em Direito pela UCPEL. Coordenadora do Programa de Pós-Graduação em Direito e Professora do Curso de Direito da UFPEL. ORCID: http://orcid.org/0000-0003-3161-0445 / e-mail: marciabertoldi@yahoo.com

3 Pós-Doutora pela Universidade Católica de Pelotas (UCPEL). Doutora em Estudos Culturais Latinoamericanos pela Universidad Andina Simón Bolívar (UASB). Mestre em Direito Indígena pela University of Calgary (UCALGARY). Mestre em Direito e Política dos Povos Indígenas pela University of Arizona. Mestre em Direito Econômico pela UASB. Professora de Direitos Humanos do Programa de Direito da UNIMAGDALENA. Pesquisa e docência em temas relacionados com terras, territórios, povos indígenas, comunidades pesqueiras artesanais, indústria extrativa e conflitos socioambientais na América Latina. ORCID: http://orcid.org/0000-0002-9119-3615 / e-mail: ifigueroa@unimagdalena.edu.co

4 Mestre em Direitos Sociais pela UFPEL. Especialista em Direito Público, com ênfase em Direito Constitucional pela Universidade Potiguar (UnP). Graduada em Direito pelo Centro Superior de Ciências Sociais de Vila Velha (UVV). Docente no Curso de Direito na FDA. ORCID: http://orcid. org/0000-0003-0102-5296 / e-mail: anacarlabrin@hotmail.com 
econômica, cultural) nunca concluído e as sobreposições de dominações que complexificaram as hierarquias, criando dominadores de dominadores e dominados que subjugam a outros dominados; (3) reflexões sobre como os dominadores coloniais mantiveram-se (a si mesmos e à nação) à margem dos ideais de modernidade e racionalidade na perspectiva iluminista; e (4) os ecos do colonialismo e da colonialidade no Brasil contemporâneo sobre as culturas indígenas, especialmente sobre suas línguas, e a resistência dos povos originários. Para tanto, ainda que sejam feitas inferências a partir de dados históricos e estatísticos em abordagem qualitativa, emprega-se o método dedutivo sempre e quando o lugar de fala da autoria referenciada seja equivalente à realidade brasileira. Conclui-se que o reconhecimento do multilinguismo e a participação dos povos originários na tomada de decisões estatais pode permitir que os direitos desses povos passem pela efetivação.

Palavras-chave: colonialismo e colonialidade; decolonialidade; direitos culturais; direitos linguísticos; diversidade linguística; história política e cultural do Brasil.

\section{LANGUAGES, BOOKS AND LAWS: THE ERASURE OF INDIGENOUS CULTURE AND RESISTANCE}

\section{ABSTRACT}

This study proposes a review on the formation of the Brazilian State, from the perspective of colonialism and coloniality, guided by the theory of decoloniality, starting from the history of languages and books to the law and the erasure of indigenous cultures. The features of the Brazilian colonization, its differences compared to Latin American neighbors, and the echoes of this process in contemporary Brazil permeate the four points in which this work is structured, namely (1) the linguistic diversity of the early Brazil and changes due to European conquest process; (2) the never completed independence process (political, economic, and cultural) and the overlap of dominations, which made the hierarchies more complex, creating dominant people who dominate other dominant people and dominated people who subjugate other dominated people; (3) the way ruling colonial powers have remained (to themselves and to the nation) on the scope of modernity and rationality ideals, from the enlightenment perspective; and, 
finally, (4) colonialism and coloniality echoes in contemporary Brazil on indigenous cultures, especially in their languages, and the resistance of the indigenous peoples. For this purpose, the deductive method is employed always and when the place of speech of referenced authors can be associated with the Brazilian reality, although sometimes inferences are made from historical and statistics data in a qualitative approach. The conclusion is that the recognition of multilingualism and the participation of indigenous peoples in State decision-making can allow the rights of these peoples to be enforced.

Keywords: colonialism and coloniality; cultural rights; decoloniality; linguistic diversity; linguistic rights; political and cultural history of Brazil.

\section{INTRODUÇÃO}

Partindo de dados sobre a história cultural do Brasil, dos 1500 até a contemporaneidade, propõe-se uma análise da fossilização do pensamento abissal (SANTOS, 2010, p. 33), excludente de visões e saberes estruturados em paradigmas outros daqueles ditos "científicos" (tal como o são os conhecimentos populares, tradicionais ou locais), e de normas coloniais (escritas ou não) que subalternizaram línguas e narrativas dos povos originários. Busca-se, ademais, apresentar características do colonialismo à brasileira, ou seja, apontar singularidades da formação do Brasil como Estado "independente" que diferem da realidade cultural-política-jurídica deste em relação ao conjunto dos países da América Espanhola e que fazem com que se necessite de intérpretes brasileiros para a proposição de uma efetiva ruptura com a colonialidade e suas marcas no Brasil contemporâneo.

Sem pretender o ineditismo, busca-se o diálogo com outras áreas do saber, pois uma proposta genuinamente decolonial só poderia decorrer de uma perspectiva multicultural e multidisciplinar e que não fracione o conhecimento em disciplinas medidas por sua serventia ao capital. Propõe-se uma pesquisa essencialmente interdisciplinar e multicultural, isto é, operando a interpretação e o tratamento de dados e saberes sobre a essência do objeto da pesquisa, qual seja, o apagamento da cultura indígena e a invisibilização de sua resistência ${ }^{5}$. Conferindo voz a intérpretes do Brasil de

5 Emprega-se a palavra no seu sentido comum, não como rubrica militar ou política. Neste artigo, a palavra resistência segue as primeiras acepções do dicionário Houaiss (2009), invocando o ato ou efeito de resistir e a capacidade de suportar adversidades, entre as quais a submissão à vontade alheia. 
diversos campos do saber e buscando o amparo em teóricos/as ${ }^{6}$ decoloniais quando a realidade de seus lugares de fala coincide com as questões pautadas, parte-se dos construtos de modernidade e racionalidade, tidos por patrimônios europeus, para demonstrar como, no Brasil, as elites coloniais, nem modernas nem muito menos racionais, sedimentaram séculos de atraso (sob os parâmetros e perspectivas eurocentristas). Assim, em que pese se recorra a aportes da história e historiografia do Brasil e das línguas e culturas no Brasil, bem como a dados demográficos e a arcabouço referencial proveniente, especialmente, dos campos da sociologia, direito e letras, este é um artigo fundamentalmente comprometido com a crítica decolonial.

Entende-se, com Catherine Walsh (2005, p. 22), que a decolonialidade não difere da descolonização. Assim, neste trabalho, a decolonialidade é compreendida como uma estratégia que vai além da transformação e que propõe rupturas com as estruturas coloniais. Esse é o principal escopo deste trabalho, que objetiva interpretar a realidade colonizada a partir dela mesma, a fim de pavimentar a sua transformação. Ainda na esteira de Walsh (2005, p. 22), deve-se entender que, enquanto o decolonialismo se preocupa com a relação histórica e seus legados, buscando transições, superações e emancipações a partir do interior da modernidade, a decolonialidade posiciona-se como uma perspectiva de exterioridade em frente à mesma relação modernidade/colonialidade, mas também ante as violências raciais, sociais, epistêmicas e existenciais vividas como parte central dela.

Desse modo, não obstante o recurso a referenciais estrangeiros, sempre e quando o lugar de fala do/a teórico/a possa ser identificado com a realidade que analisamos, buscam-se esforços para confrontar, desde o próprio e desde as lógicas-outras e pensamentos-outros, a desumanização, o racismo e a racialização, bem como a negação e destruição de campos-outros do saber (WALSH, 2005, p. 22) e mesmo de línguas-outras. Por essa razão, demonstra-se como algumas línguas e as narrativas indígenas resistiram e seguem conferindo diversidade ao patrimônio linguístico e cultural brasileiro, embora subalternizadas e constantemente ameaçadas.

Essas propostas são organizadas em quatro pontos centrais de análise.

\footnotetext{
Não se a compreenda, neste artigo, como termo a indicar a ação organizada paramilitar, termo que configura a $11^{\mathrm{a}}$ acepção no Houaiss (2009).

6 A revisão da linguagem empregada neste artigo seguiu o Manual pedagógico sobre uso da linguagem inclusiva não sexista, da Comissão Permanente de Gênero e Direito das Mulheres da Reunião de Altas Autoridades em Direitos Humanos e Chancelaria do MERCOSUL (2018), que recomenda emprego de barras diagonais, sem espaço, em substantivos e adjetivos de dois gêneros, para refutar a invisibilização do feminino promovida pela suposta neutralidade do emprego do masculino para referência a coletividades formadas por mulheres e homens.
} 
O primeiro foca na diversidade linguística do Brasil originário e nas mudanças decorrentes da chegada dos conquistadores europeus. $\mathrm{O}$ segundo aborda o processo de independência (política, econômica, cultural) nunca concluído e as sobreposições de dominações que complexificaram as hierarquias, criando sobreposições de dominação (dominadores/as de dominadores/as e dominados/as que subjugam a outros dominados/as). No terceiro ponto, demonstra-se como a dominação colonial manteve-se (a si mesma e à nação) à margem dos ideais de modernidade e racionalidade na perspectiva iluminista. O quarto e último ponto traz os ecos do colonialismo e da colonialidade no Brasil contemporâneo sobre a cultura indígena, especialmente sobre suas línguas, e a resistência dos povos originários no empenho para a efetivação de seus direitos culturais ${ }^{7}$ e linguísticos ${ }^{8}$.

Emprega-se o método dedutivo sempre e quando o lugar de fala do teórico referenciado possa ser identificado com a realidade brasileira. A partir da colonialidade do poder, do ser e do saber indígena e da resistência indígena em conservar sua cultura, especialmente a língua, elemento constitutivo daquela, depreende-se que o reconhecimento do multilinguismo e a participação dos povos originários na tomada de decisões estatais (interculturalidade) pode permitir que os direitos culturais e linguísticos desses povos passem pela efetivação.

\section{A DIVERSIDADE LINGUÍSTICA DO BRASIL ORIGINÁRIO}

Tal qual as pessoas que colonizaram o Brasil, que se valiam não só da língua portuguesa, mas também do latim e do castelhano (e, posteriormente, do francês e do inglês) como língua comum para a transmissão do saber e para as questões comerciais e diplomáticas, os povos originários, subjugados pela colonização europeia, também se dedicavam a adquirir línguas de outras tribos para com elas se relacionar. Assim, conforme Lia Wyler (2003, p. 31), estima-se que, no século XVI, o Brasil era um território poliglota onde conviviam falantes de "centenas de línguas e dialetos que contemporaneamente podem ser classificados em 102 grupos e três ramos linguísticos: o tupi, o macro-gê e o aruaque". Em 1500, os/as falantes dessas línguas distribuíam-se homogeneamente pelo

7 Em âmbito internacional, ver: art. 15 do Pacto Internacional de Direitos Econômicos, Sociais e Culturais; art. 14 do Protocolo de San Salvador; art. 17 da Carta Africana de Direitos Humanos e dos Povos; art. 42 da Carta Árabe de Direitos Humanos; art. 32 da Declaração de Direitos Humanos da ASEAN. Em âmbito nacional, ver: art. 225 da Constituição Federal de 1988.

8 Ver Declaração Universal de Direitos Linguísticos. 
território hoje conhecido por Brasil e travavam relações e contatos entre si, razão pela qual se supõe "que tal diversidade linguística estimulasse o bilinguismo - talvez o plurilinguismo - e a tradução intergrupal, pois, onde houve oportunidade, desenvolveram-se línguas francas" (WYLER, 2003, p. 31). São exemplos de línguas francas o abanheenga, de tronco tupi (posteriormente rebatizado pelo Padre José de Anchieta para nheengatu, ou bela língua), falado no litoral, e o cariri, do tronco macro-gê, no interior do nordeste (WYLER, 2003, p. 31).

A existência dessas línguas francas e sua apropriação a serviço da empresa colonial por homens e mulheres que promoveram a conquista do Brasil desempenharam papel significativo no processo de espoliação do território e dominação dos povos originários conformando um genuíno processo eurocentrista. Este processo implica na naturalização de que as riquezas e seres humanos do mundo todo estavam a serviço de colonizadores/as e que seus saberes e línguas-cultura forjariam uma ideia universal, ou seja, válida para todos os povos do mundo. O processo eurocentrista incide sobre vários aspectos, entre os quais o "linguístico (as línguas europeias, derivadas, sobretudo, do latim e do grego, se tornam as únicas nas quais é possível expressar o conhecimento verdadeiro e válido)", tendo em consideração que indígenas "não têm língua senão dialeto" (GARCÉS, 2007, p. 220).

Por esse processo, não obstante a riqueza linguística e cultural do Brasil originário até a conquista europeia, os manuais empregados na formação dos estudantes brasileiros não raro apresentam como primeiro capítulo o Brasil dos 1500, como se a chegada do/a colonizador/a às Américas tivesse inaugurado as noções de história, cultura, língua e literatura ${ }^{9}$. É como se o processo de colonização constituísse "o grau zero a partir do qual são construídas as modernas concepções de conhecimento e direito" (SANTOS, 2010, p. 36). Mas não só; é como se não tivesse havido nada nas Américas antes da chegada de homens e mulheres provenientes da Europa, como se a cultura colonizada fosse um receptáculo vazio tal qual a alma de seus habitantes originários, seguindo a interpretação da bula Sublimis Deus, de 1537, por meio da qual o Papa Paulo III postulou que habitantes das terras conquistadas seriam "selvagens", de anima nullius (SANTOS, 2010, p. 37).

9 À guisa de exemplo: "O que para a nossa história significou uma autêntica certidão de nascimento, a Carta de Caminha a D. Manuel, dando notícia da terra achada, insere-se num gênero copiosamente representado durante o século XV em Portugal e Espanha: a literatura de viagens" (BOSI, 2006, p. 14 , grifos nossos). 
O esforço por negar a pessoas indígenas uma alma e uma humanidade, bem como uma história, uma religião, uma língua e uma cultura, relacionava-se à intenção de legitimar juridicamente a espoliação de suas riquezas, a destruição de suas comunidades e de submetê-las a trabalhos forçados. A propósito, com Quijano (2005, p. 207), é preciso recordar que a mortandade de índias e índios nas primeiras etapas da colonização espanhola decorreria não das enfermidades ou das batalhas pela conquista do território, como comumente se alardeia, mas do fato que seus corpos tenham sido usados como mão-de-obra descartável, forçados a trabalhar até a exaustão final: a morte. Nas Américas, a escravidão foi deliberadamente instituída e organizada para transformar seres humanos em mercadorias destinadas a produzir mercadorias para o mercado mundial e servir, assim, ao capitalismo (QUIJANO, 2005, p. 219).

Em 1500, haveria, no Brasil, em torno de 4 milhões de pessoas indígenas; em 1823, restava menos de 1 milhão: os homens e mulheres "escaparam ou se miscigenaram ou foram empurrados para o interior do país. A miscigenação se deveu à natureza da colonização portuguesa: comercial e masculina" (CARVALHO, 2002, p. 20). A escravização dos povos originários foi proibida por lei em 1560 por razões religiosas, a "oposição decidida dos jesuítas" (CARVALHO, 2002, p. 20), mas também por pragmatismo, pois estavam sendo rapidamente dizimados. A partir da proibição de escravizar indígenas, porém, intensificou-se a escravização de povos africanos e, além desta, outra prática característica da formação do Brasil: a desobediência às leis.

A desobediências sistemática às leis e as origens do paternalismo à brasileira, conforme Carvalho (2002, p. 21-22), decorrem da carência de estruturas de justiça na colônia:

\footnotetext{
A justiça do rei tinha alcance limitado, ou porque não atingia os locais mais afastados das cidades, ou porque sofria oposição da justiça privada dos grandes proprietários, ou porque não tinha autonomia perante as autoridades executivas, ou, finalmente, por estar sujeita à corrupção dos magistrados. Muitas causas tinham de ser decididas em Lisboa, consumindo tempo e recursos fora do alcance da maioria da população. O cidadão comum recorria à proteção dos grandes proprietários, ou ficava à mercê do arbítrio dos mais fortes.
}

Desprovidas de proteção efetiva contra o arbítrio, as pessoas indígenas seguiram sendo sequestradas, ao arrepio da lei, para imposição de trabalhos forçados, sobretudo por bandeirantes paulistas, que "apenas remota e nominalmente estavam a serviço de Portugal e, não raro, desobedeciam 
às ordens de El-Rei” (ALMEIDA, 2013, p. 24). A escravização de pessoas indígenas conformava a desobediência mais frequente.

Acredita-se que uma das consequências dos ataques sistemáticos aos povos originários durante o processo de colonização tenha sido a atual concentração de indígenas na região norte do Brasil. ${ }^{10}$ Até a chegada de Cabral, mulheres e homens indígenas distribuíam-se homogeneamente por todo o território, concentrando-se um pouco mais ao litoral; contudo, ao longo do século XVI, sucessivas ondas migratórias rumaram ao norte. No plano linguístico, é possível que seja decorrência desses movimentos migratórios, e do contato entre povos originários antes não comunicantes, a disseminação de uma "língua franca ou geral de base tupi por todo o território colonial" (WYLER, 2003, p. 31), inclusive entre pessoas a serviço da colonização, para o que muito concorreram os jesuítas. Essa língua, o nheengatu ${ }^{11}$, foi legada também a pessoas escravizadas de origem africana ${ }^{12}$ e era tão disseminada que ficou conhecida como "língua geral" e perdurou até o século XIX, chegando a competir com o português e o francês na decisão sobre o idioma nacional durante a Constituinte de 1823 (WYLER, 2003, p. 58).

Para essa Babel do Brasil, também os as pessoas de origem europeia deram a sua contribuição. Afinal, os portugueses ${ }^{13}$ valiam-se do latim como fonte de cultura e espiritualidade, do castelhano e do francês. Este idioma, embora de uso mais restrito, tinha tal relevância entre as camadas dirigentes que chegou a ser cogitado como língua oficial da nação independente. Ainda que isso não se tenha concretizado (talvez porque a própria Constituinte tenha sido dissolvida por Dom Pedro I, que outorgou a Constituição

10 Conforme o IBGE (2012, p. 10) a partir de dados do censo de 2010: é no Estado do Amazonas que está a maior população autodeclarada indígena do Brasil (168,7 mil) e, em Roraima, a maior concentração relativa no total da população (11\%).

11 Nheengatu significa "bela língua", nome dado por José de Anchieta à língua de base tupi. Sobre Anchieta, diz Wyler (2003, p. 40): "Sua Arte da gramática na língua mais usada na costa do Brasil foi reproduzida inicialmente em manuscrito e mais tarde impressa em Coimbra, em 1595. Um século após o achamento, o nheengatu ensinado e divulgado pelos jesuítas por todo o Brasil firmou-se como língua oficiosa da colônia".

12 No que tange às línguas dos escravizados de origem africana, Raimundo de Nina Rodrigues as classificaria em três grandes grupos: chamitas, sudaneses e bantos, sendo que possivelmente se tenha adotado o nagô ou ioruba (do grupo sudanês) como língua franca na Bahia e o quimbundo ou conguês (do grupo banto) no norte o no sul do Brasil (WYLER, 2003, p. 34). No entanto, acredita-se que, em função da dispersão forçada pelo conquistador português, o negro, ao desembarcar, tenha sido obrigado a aprender o português para atender ao colonizador e o tupi, a língua franca, para se entender com os companheiros de escravidão (WYLER, 2003, p. 34). Afinal, "a importação portuguesa seguia a política de variar o máximo possível a composição étnica e linguística de cada leva, mantendo dispersos os grupos tribais nucleares de modo a evitar a sua unidade e insubmissão" (WYLER, 2003, p. 33).

13 Às mulheres portuguesas e brasileiras foi negado o acesso ao letramento básico até o século XIX mesmo entre a elite. $\mathrm{O}$ analfabetismo feminino era encarado como virtude. 
de 1824) a mera inclusão do francês entre as propostas idiomáticas de oficialidade para a nação que se tornava independente comprova que a formação do Brasil não se deu somente pela sobreposição da cultura colonizada pela colonizadora; havia também a dominação (econômica e cultural) de dominadores/as, ou seja, a existência de dominadores/as de dominadores/as. A sobreposição de dominações complexificou as relações sociais no Brasil, como se passa a desenvolver no ponto que segue.

\section{UMA INDEPENDÊNCIA NUNCA CONCLUÍDA E AS SOBREPOSIÇÕES DE DOMINAÇÕES}

O Brasil tornou-se independente em 1822, em processo intermediado pela Inglaterra e assumindo o compromisso de pagar a Portugal uma indenização de 2 milhões de libras esterlinas. Esse simulacro de descolonização, que perpetuou a casa de Bragança na monarquia, recebeu apoio das elites locais temerosas de que se repetisse em solo brasileiro o exemplo do Haiti, onde escravizados/as rebelados/as proclamaram a independência e expulsaram a população branca (CARVALHO, 2002, p. 27). Por certo, uma independência como a brasileira, construída a partir do temor ao poder popular e intermediada por uma nova nação dominante, não seria capaz de encorajar as necessárias alterações nas dinâmicas sociais; nem mesmo a República, proclamada em 1889, o faria. A última nação a abolir a escravização de seres humanos se conformaria privilegiando o construto de raça para atribuição de prestígio, pois nem mesmo os homens brancos e inseridos em estruturas de conforto material e simbólico chegaram a se credenciar como partícipes dos rumos da nação e seguiram sendo majoritariamente analfabetos. Nesse sentido, nunca se chegou a criar, no Brasil, condições materiais para se romper com as amarras do poder e pensamento colonial.

Tal característica, por certo, não é exclusividade brasileira. Conforme Quijano (2005, p. 237), o Estado-nação mestiço e fraturado de toda a América não inglesa acabou por consolidar-se sobre pilares contraditórios, frágeis e problemáticos como: (1) os limitados processos de descolonização/democratização, mesmo após independências; (2) o limitado, mas real processo de homogeneização racial por meio do genocídio dos povos não brancos; (3) um sempre frustrado processo de homogeneização cultural; (4) imposição da ideologia de democracia racial, que mascara a discriminação. 
Assim, o construto de raça e as complexas hierarquias de dominação acabaram por se consolidar como o principal canal de atribuição de valor e prestígio. Em outras palavras, no capitalismo mundial moderno/ colonial, as pessoas se classificam e são classificadas segundo três diferentes perspectivas articuladas pela colonialidade do poder: trabalho, gênero e raça (QUIJANO, 2007, p. 115). A cor da pele foi definida como a marca diferencial mais significativa entre dominantes ou superiores (mulheres e homens da Europa) e o conjunto de dominados/as ou inferiores (mulheres e homens não europeus). Desse modo, atribuiu-se a pessoas dominadoras/ superiores europeias a raça branca e a todas as pessoas dominadas/inferiores não europeias o atributo de raças "de cor" (QUIJANO, 2007, p. 120).

No que tange ao trabalho, é de se recordar que as pessoas ditas "de cor" foram historicamente relegadas às atividades braçais, ao passo que as camadas brancas atribuíam a si mesmas a tarefa de pensar (e mandar). Os filhos de elites eram enviados à metrópole para estudar na Universidade de Coimbra. No Brasil, foram proibidas as universidades e as tipografias (bem como a circulação de material impresso) até 1808, o que colocou o Brasil em posição de franca desvantagem mesmo em comparação com os países vizinhos da América Espanhola. A tipografia só passou a ser admitida com a vinda de Dom João VI e, mesmo após a fundação da Impressão Régia, em 1808, a liberdade de imprimir era limitada e havia rigoroso controle alfandegário, com controle de impressos trazidos do exterior e confisco de títulos que não aqueles constantes da lista de autorizados pelas autoridades (WYLER, 2003, p. 77).

No que tange ao plano educacional, Carvalho (2007, p. 23) traça a comparação do Brasil com a Colônia Espanhola:

\begin{abstract}
A Coroa portuguesa, em contraste com a espanhola, não permitiu jamais a criação de universidades na colônia. Na época da Independência, havia 23 universidades na parte espanhola e nenhuma na parte portuguesa. Cerca de 150 mil pessoas haviam se formado nas universidades coloniais espanholas, ao passo que apenas 1.242 brasileiros tinham passado pela Universidade de Coimbra. O Brasil independente não alterou radicalmente essa política. Apenas quatro escolas superiores foram criadas até 1830 e as primeiras universidades só apareceram no século XX. A educação superior pública manteve sua função de treinar elites.
\end{abstract}

Hallewell (2012, p. 94) também sustenta números: 720 teriam sido os brasileiros formados em Coimbra, a única universidade de todo o império português, entre os anos de 1775 e 1822 . No mesmo período, 7.850 bacharéis e 473 doutores teriam sido formados só pela Universidade do México. 
Na análise de Carvalho (2002, p. 32), esse quadro impactou na ausência de condições para uma cultura cívica no Brasil:

Os brasileiros tornados cidadãos pela Constituição eram as mesmas pessoas que tinham vivido os três séculos de colonização nas condições que já foram descritas. Mais de $85 \%$ eram analfabetas, incapazes de ler um jornal, um decreto de governo, um alvará da justiça, uma postura municipal. Entre os analfabetos incluíam-se muitos dos grandes proprietários rurais. Mais de $90 \%$ da população vivia em áreas rurais, sob controle dos grandes proprietários. Nas cidades, muitos votantes eram funcionários públicos controlados pelo governo.

Apesar do analfabetismo massivo, que incluía camadas dirigentes, comumente referidas como "elites", não é de se estranhar que tenha surgido, durante a Constituinte de 1823, a proposta de que a língua oficial da nova nação pudesse ser o francês; tratava-se da possibilidade de eleger o idioma a dominar dominadores/as e afastar as grandes massas de dominados/as da participação política, o que parece ter sido sempre uma conjectura no Estado Brasileiro. Mesmo após a dissolução da Assembleia Constituinte e a outorga da Constituição Imperial de 1824, que elegeu o português como idioma oficial, a França seguiria confirmando o seu papel de domínio cultural, exportando livros para o Brasil e abrindo livrarias na nova nação (WYLER, 2003, p. 84), até porque os impostos sobre a importação de papel inviabilizavam a consolidação de uma indústria brasileira de livros e impressos.

A língua, um constructo da cultura, estava dominada. Nesse sentido, Mignolo (2003, p. 669) infere que a ciência (conhecimento e sabedoria) não se pode separar da língua, pois esta não é apenas um fenômeno cultural no qual os povos encontram sua identidade; é também o lugar onde o conhecimento está inscrito. E, se as línguas não são coisas que os seres humanos têm, senão algo que são, a colonialidade do poder e do saber engendra, pois, a colonialidade do ser.

Para Antonio Candido (1989, p. 143), a consequência natural deste quadro foi a ausência de condições materiais para o livro e a literatura e a pouca de resistência às pressões externas:

[...] ligam-se ao analfabetismo as manifestações de debilidade cultural: falta de meios de comunicação e difusão (editoras, bibliotecas, revistas, jornais); inexistência, dispersão e fraqueza dos públicos disponíveis para a literatura, devido ao pequeno número de leitores reais (muito menor que o número já reduzido de alfabetizados); impossibilidade de especialização dos escritores em suas tarefas literárias, geralmente realizadas como tarefas marginais ou mesmo amadorísticas; falta de resistência ou discriminação em face de influências e pressões externas. 
O processo de independência e a proclamação da República não alteraram o quadro educacional da antiga colônia, e o Brasil manteve-se majoritariamente analfabeto até a década de 1950. No primeiro levantamento demográfico da história brasileira, em 1872, foram computadas 8.365 .997 pessoas que não sabiam ler nem escrever $(84,24 \%)$ contra apenas 1.564 .481 com conhecimento de letras (IBGE, 2014). Apesar disso (ou talvez por isso mesmo), em 1881, a Câmara de Deputados aprovou lei que introduzia o voto direto, eliminava o primeiro turno nas eleições, e, ao mesmo tempo, instituía a comprovação de renda mínima de 200 mil-réis para alistamento e proibia o voto dos analfabetos. Na análise de Carvalho (2002, p. 39):

As consequências logo se refletiram nas estatísticas eleitorais. Em 1872, havia mais de 1 milhão de votantes, correspondentes a $13 \%$ da população livre. Em 1886, votaram nas eleições parlamentares pouco mais de 100 mil eleitores, ou $0,8 \%$ da população total. Houve um corte de $90 \%$ do eleitorado. O dado é chocante, sobretudo se lembrarmos que a tendência de todos os países europeus da época era na direção de ampliar os direitos políticos. [...] O mais grave é que o retrocesso foi duradouro. A proclamação da República, em 1889, não alterou o quadro.

Considerando que foi apenas por ocasião do Censo de 1960, que, pela primeira vez, constatou-se que a população alfabetizada havia superado o contingente iletrado, e que somente com a promulgação da Emenda Constitucional $\mathrm{n}^{\circ} 25$, de 15 de maio de 1985 , quem não soubesse ler poderia exercer o direito (facultativo) a voto, é possível auferir que a maioria dos/ as brasileiros/as permaneceu excluída do exercício mais básico da cidadania, o voto, até meados do século XX.

A inserção tardia do Brasil num projeto de modernidade teve por causa e consequência a sobreposição de dominações. Cultural e literariamente, a França seguiria desempenhando o seu papel de ditadora de tendências até a década de 1930 do Século XX, quando, em decorrência das crises e guerras europeias, ${ }^{14}$ associadas a pressões internas (artísticas, como a Semana da Arte de 1922, e políticas, como o plano Vargas para a consolidação de uma indústria nacional do livro), o livro brasileiro passaria a ser competitivo em seu próprio sistema econômico, e os temas do Brasil, alardeados pelo Romance de 30, passaram a encontrar respaldo entre editoras e leitores/as interessados/as. Essa relativa independência cultural não tardou a ser afetada por outra cultura imperialista, os Estados Unidos. Em

14 De 1928 a 1936, a aquisição de livros franceses despencou 94\%, como, aliás, ocorreu com todas as demais importações em função da desvalorização do mil-réis. Pela primeira vez, o livro brasileiro seria competitivo em seu próprio mercado nacional, intensificando o boom editorial que desde o primeiro pós-guerra já se podia observar (HALLEWELL, 2012, p. 440). 
suma, a colonialidade do ser, do poder e do saber seguiram impondo-se constantemente.

No plano político e econômico, no entanto, não é possível afirmar ter havido ruptura com nações dominadoras. Econômica e politicamente, a Inglaterra esteve diretamente envolvida com episódios centrais da história do Brasil, como a vinda da família real para o Brasil em 1808, o processo de independência em 1822, a abolição da escravatura em 1888 e com diversos eventos político-militares nesse interregno. Culturalmente, a França ditou tendências e exportou legitimidade de pensamento até meados do século XX. Na segunda metade do século XX, os Estados Unidos assumiram o protagonismo das dominações - e não só no plano político.

Acentuando esforços durante a Segunda Guerra Mundial (1939-1945), que alavancariam o domínio estadunidense em meados do século XX, foi criado o Office of the Coordinator of Interamerican Affairs (CIAA), que supostamente promovia o estreitamento de laços de "amizade" entre a América inglesa e as demais Américas. Era a concretização do chamado soft-power. Compreendendo os reflexos da cultura na política, a companha estadunidense de disseminação de sua própria cultura e controle de todas as culturas-outras veio associada à promoção de escolas de ensino da língua inglesa, ao financiamento de traduções de obras escolhidas para disseminar o american way of life e o cinema. Walt Disney foi colaborador da CIAA e, no início da década de 1940, criou o personagem Zé Carioca e produções com foco no Brasil como o filme The three caballeros ("Você já foi à Bahia?").

Nesse contexto, é possível afirmar que Portugal nunca chegou a se forjar como Estado absolutista porque os/as colonizadores/as do Brasil estiveram sempre subjugados/as a outras culturas dominadoras. Sob outra ótica, também é necessário reconhecer que se forjou a dominação de dominados/as e o paternalismo, o que minou a consolidação de um sentimento de unidade (nacional, de classe, de gênero, de raça etc.). A escravização de pessoas, por exemplo, sendo prática tão arraigada no Brasil, testemunhou pessoas escravizadas que escravizavam outras pessoas ${ }^{15}$ sempre e quando isso era possível. O aluguel de corpos escravizados era também prática frequente; alguns eram alugados para cumprir tarefas; outros, para mendigar.

Esse sistema de dominações impediu a solidariedade entre pessoas em situação de opressão e mitigou os valores de classe. ${ }^{16}$ Seja na vida cotidiana 15 A propósito, recorde-se, na literatura, o conto $O$ caso da vara, de Machado de Assis. 16 Segundo Almeida (2013, p. 28-29): "Havia, no Brasil, escravos que tinham escravos. Escravos que 
da colônia, seja na definição de normas colonizadoras, essa sobreposição de dominações perturbou a integração social e a solidariedade necessárias à consolidação dos nacionalismos (bem como quaisquer outros elementos associativos calcados na equivalência entre seres humanos). Afinal, uma parcela da população esteve sempre subjugada a outra, como inimigas entre si (CARVALHO, 2002, p. 50), o que se perpetuou e se evidencia ainda no Brasil contemporâneo, que chega ao século XXI como o décimo país mais desigual do mundo e onde os $10 \%$ mais ricos concentram $43,1 \%$ da massa total de rendimentos no país e o $1 \%$ do topo concentra 33,8 vezes os rendimentos de metade "de baixo" da população brasileira (IBGE, 2019). ${ }^{17}$

Com efeito, os três construtos apontados por Quijano (2014): trabalho, gênero e raça, heranças do colonialismo, estão a tal ponto fossilizados na estrutura (social e cognitiva de homens e mulheres) do Brasil como força natural e legitimadora de condutas predatórias sobre os demais elementos existentes no planeta, sejam recursos naturais, sejam seres humanos (QUIJANO, 2014, p. 855), que se tornaram "naturais" (e, para muitas pessoas, invisíveis ou inverossímeis). Mas há outro construto que demanda análise cuidadosa do/a pesquisador/a atento/a: o de língua. A imposição de uma língua (inclusive atribuindo prestígio a certas pronúncias desta) e o consequente apagamento de outras várias formas de expressão comunicativa, conformaram (juntamente a ou talvez até mais do que a proibição de universidades e tipografias e o analfabetismo em massa) a forja e a marca de uma independência nunca concluída, o que deu campo às colonialidades e as segue promovendo.

\section{NEM MODERNO, NEM RACIONAL; APENAS DOMINANTE}

Inserido com séculos de atraso num projeto de modernidade, o Brasil seguiu sendo majoritariamente incapaz de ler até meados do século XX. A inserção, tardia e precária, nos ideais Iluministas de ensino laico e para

compravam a liberdade de seus familiares, mas não conseguiam comprar a própria (eram escravos de ordens religiosas, ou valiosos demais, ou estavam hipotecados como garantia de dívidas de seus senhores). Escravos que formavam cooperativas, verdadeiros consórcios de liberdades, depositando seus ganhos nessas sociedades de complexa administração econômica, conquistando, aos poucos, a liberdade; quando livres, continuavam contribuindo para a liberdade dos demais. Existia o fenômeno generalizado da "brecha camponesa", que era quase um "direito" dos escravos em muitas regiões. Cultivavam sua própria "roça" aos domingos, o que era bom para o senhor que se eximia da responsabilidade da subsistência e melhorava a dieta de seus escravos. Alguns acumularam pecúlio suficiente para se alforriarem".

17 Segundo o IBGE (2019): “Em 2018, o rendimento médio mensal real do 1\% da população com maiores rendimentos era de $\mathrm{R} \$ 27.744$, o que corresponde a 33,8 vezes o rendimento dos $50 \%$ da população com os menores rendimentos ( $\mathrm{R} \$ 820)$ )". 
todos e todas nunca garantiu acesso democrático nem a consolidação do que se designou civilização ocidental secular, nem muito menos rompeu com o pensamento abissal propulsado pelo colonialismo e referendado pela colonialidade.

Assim, e como se demonstrou no ponto anterior, a dominação da América Portuguesa e as camadas que a apoiavam não eram mais detentoras dos capitais de modernidade e racionalidade que as pessoas indígenas e as indigenizadas, ou seja, aquelas que historicamente foram vitimizadas pela colonialidade (QUIJANO, 2014, p. 859). Apesar disso, o discurso de dominação sustentou-se em hierarquias baseadas em intelecto, e não em força bruta. Mesmo que se recorde, com Quijano (2005, p. 214), que as grandes vias de transporte, a agropecuária, o calendário, a matemática, as tecnologias metalíferas, a filosofia e também as armas, as guerras, a história e as línguas existiam muito antes da formação da Europa, consolidou-se o conceito de modernidade e de racionalidade como patrimônios exclusivos de pessoas de proveniência europeia. A humanidade atual, em seu conjunto, configurou-se, assim, como o primeiro sistema-mundo historicamente conhecido (SANTOS, 2010).

Na formação do Brasil, a ânsia do ter, calcada na exploração (seja da natureza, seja de seres humanos), o descaso pela educação primária e a constituição de elites dirigentes que eram ou demasiadamente estrangeirizadas ou essencialmente iletradas contrastavam com a visão dos povos originários. De valores mais harmônicos e processos educativos afeitos ao bem-estar, ao perspectivismo e ao corazonar $^{18}$ os pensares dos povos originários foram subjugados pelo processo de conquista. Convém uma breve reflexão histórica sobre a questão.

A partir de 1549, com a instalação do governo geral, escolas e livros desembarcaram no Brasil. Contudo, o ato de Dom João III que delegou aos jesuítas o monopólio do ensino e da catequese na nova colônia aclarava que a educação dar-se-ia a título de missões; o ensino visaria apenas

18 Interessante passagem descrita por KAHMANN (2017, p. 58) define o termo corazonar: "O ocidente dá primazia à razão e ao domínio da emoção e dos sentimentos, que são considerados um empecilho ao conhecimento científico. Temos que manter distância em termos afetivos em relação ao objeto. $\mathrm{O}$ próprio termo objeto denota a relação de coisificação e de desconsideração aos sentimentos alheios, considerada ideal ao pensamento ocidental. Tanto o pesquisador, quanto o que vai ser pesquisado, é desvencilhado de sua dimensão afetiva, dimensão essa considerada resquício de nossa origem animalesca e que deve ser eliminada para reinar a razão. Assim, a razão seria o que nos diferencia dos outros animais, sendo, portanto, o que nos tornaria humanos. Já no pensamento ameríndio para conhecer é preciso, ao invés de objetificar, personificar. E só se conhece objetivamente quando se assume a perspectiva do outro, o que inclui sentimentos e emoções. Ao discorrer sobre uma origem humana em comum a todos os seres, essa humanidade inclui não só a razão, mas também o coração. Corazonar é essa forma de conhecimento que alia o coração à razão". 
à formação de sacerdotes para a colônia (WYLER, 2003, p. 54). Estavam assentadas, pois, as bases para uma educação de cunho moral e pouco cientificista, com a qual nunca se chegou a romper, e de acesso excludente. Há relatos de que o padre Manuel da Nóbrega teria feito chegar à rainha Catarina os apelos dos indígenas para que se fundassem escolas também para as meninas. Mas, por tratar-se o pedido de "uma extravagância que ainda não entrara nas cogitações nem do mais ilustrado renascentista" (WYLER, 2003, p. 54), não recebeu atenção da Corte. A educação jesuítica voltava-se a homens brancos, os considerados capazes de elevar aos estudos superiores necessários para disseminar o cristianismo.

Durante dois séculos, apenas os jesuítas estiveram autorizados a lecionar no Brasil. Nesse período, compuseram bibliotecas que constituíram centros de grande importância na formação cultural das elites coloniais. Apesar disso, ao buscar romper com essa tradição, os detentores do poder agiram com as regras que conheciam: as armas em vez do diálogo, a destruição em vez da transição. Os jesuítas foram expulsos, o nheengatu foi proibido, as bibliotecas foram desmanteladas. Segundo Wyler (2003, p. 56): "ao tempo da expulsão dos jesuítas e do desmantelamento de suas bibliotecas em 1759, elas somavam 12 mil volumes no Maranhão e no Pará, 5 mil 434 volumes no Rio de Janeiro, 15 mil em Salvador, obras em francês, espanhol, inglês, italiano, latim e grego". Com as reformas do Marquês de Pombal, Portugal, tardia e atrapalhadamente, tentava instituir a educação formalmente inspirada nos ideais Iluministas. Não obstante, excetuada a perseguição às línguas de origens indígenas e às revoltas pela expulsão dos jesuítas, ${ }^{19}$ a Reforma Pombalina não rompeu com o atraso e a elitização dos parâmetros educacionais da colônia ${ }^{20}$.

Tampouco em Portugal a tal reforma apresentou os resultados esperados. Entre dominantes (sempre subjugados/as por dominações outras), a escassez de pessoal qualificado seguiu sendo tão significativa que obrigava

19 Depois de dois séculos de domínio educacional jesuítico, o Estado reassumiu - "de maneira completamente inadequada" (CARVALHO, 2002, p. 22) - o controle da educação, seja em Portugal, seja no Brasil. Para o projeto de Pombal, era preciso ampliar-se o uso da língua portuguesa, a única marca indiscutível de associação ao poder colonial e de controle por parte deste. Como consequência, no sul do Brasil eclodiu a "Guerra Guaranítica" (1753-1756). No Norte, em 1755, em resistência aos reflexos da política pombalina no Brasil, a língua portuguesa foi banida de São Luiz e Belém (WYLER, 2003, p. 40), mas, em 1759, foram expulsos os últimos jesuítas e suas últimas bibliotecas foram desmanteladas.

20 Conforme Lia Wyler (2003, p. 56): “A elitização do ensino não se extinguiu com a expulsão dos jesuítas, conforme apregoam os defensores da reforma feita pelo marquês de Pombal no reinado de Dom José. Mesmo depois, excetuando-se os seminários e as aulas monásticas, ambos frequentados pela elite, só havia aulas régias (escolas) nas cidades e vilas mais importantes e em número limitado. Os mestres eram improvisados e mal remunerados: a Bahia em 1777 contava apenas com dois professores; Santa Catarina em 1823 não possuía uma única cadeira de ensino público". 
a incorporação de brasileiros à burocracia, flexibilizando, assim, os papéis inerentes a uma estrutura colonial. Desse modo, "comerciantes nascidos no Brasil, tendo estudado na Universidade de Coimbra ou se tornado cortesãos em Lisboa, adquiriram prestígio social muito mais difícil de conseguir para um criollo nascido no Peru ou em Buenos Aires" (ALMEIDA, 2013, p. 24). E, talvez por isso, tenha-se cristalizado a falácia de que o processo de colonização brasileira não tenha sido tão vertical ou tão cruel quanto o dos países da América Hispânica. Ledo engano; o colonialismo (e a colonialidade) à brasileira, com todas as suas sobreposições de dominações, é tão mais cruel quanto mais naturalizado, e segue vigente no Brasil contemporâneo. É o que se passa a expor, abordando notadamente sobre as línguas indígenas.

\section{DA COLONIZAÇÃO À COLONIALIDADE LINGUÍSTICA E A RESISTÊNCIA INDÍGENA}

Já alertava Boaventura de Sousa Santos (2010, p. 39) a respeito do pensamento abissal: "esta realidade é tão verdadeira hoje como era no período colonial". O pensamento abissal continua a operar atribuindo valor a mercadorias e ideias "importadas". No plano cultural, os best-sellers, ou seja, obras provenientes de culturas colonizadoras e que são assim chamadas não porque vendem muito, mas porque são concebidas para vender muito (especialmente a culturas dominadas), são responsáveis por cerca de 70\% das traduções circulantes no mundo (TORRES, 2009). Construídas a partir de critérios como a simplicidade da linguagem e a criação de imagens estereotipadas, essas obras conformam o oposto da abertura para o reconhecimento e emancipação do outro, o oposto à diversidade e à renovação do sistema por meio do ingresso de novas palavras e pensamentos para o enriquecimento de um idioma ou das ideias circulantes em uma nação, que seriam os fundamentos das traduções na perspectiva romântica.

Isso demonstra que todo o processo de educação/cultura do Brasil encontra-se ainda arraigado aos modelos voltados para a consagração da língua, da cultura e do pensamento de colonizadores/as. Nos dizeres de Sachs (2008, p. 73), da forma como se encontra hoje, a educação ainda é uma educação antidesenvolvimento, que não emancipa, que não guarda o necessário respeito com a diversidade e que deveria existir em decorrência do autêntico processo de formação cultural. Esse processo acarreta o apagamento daquilo que é diverso ao modelo eurocentrista, a desconsideração 
do que é singular e genuíno, do que é um pensamento diverso do sistema-mundo europeu (ou euro-estadunidense), capitalista/patriarcal e moderno/ colonial (GROSFOGUEL, 2005).

Para Khatibi (1993, p. 19) urge encontrar um pensamento outro, "um modo de pensar que não se inspire em suas próprias limitações e que não aspire a dominação e humilhação; um modo de pensar que seja universalmente marginal, fragmentado e não consumado; e, enquanto tal, um modo de pensar que por ser universalmente marginal e fragmentado não é etnocida". Mignolo (2003) o designa de pensamento fronteiriço ou gnosis fronteiriça, ou seja, uma nova dimensão epistemológica, uma máquina de descolonização intelectual e, portanto, de descolonização política e intelectual.

Como se vem demonstrando ao longo deste trabalho, ainda se impõe a linha abissal de Boaventura de Sousa Santos (2010, p. 34): de um lado da linha, estão as sociedades civilizadas, de outro, os territórios coloniais, onde "não há conhecimento real; existem crenças, opiniões, magia, idolatria, entendimentos intuitivos e subjetivos que, na melhor das hipóteses, podem tornar-se objetos ou matéria-prima para a inquirição científica". Essa linha abissal é tão imponente e naturalizada que, do lado de cá (da perspectiva do/a colonizado/a), parece nem sequer existir pensamento ou cultura. Sem sequer refletir sobre essa linha, apagam-se línguas e narrativas outras, que não as línguas do domínio euro-estadunidense.

Não obstante, as línguas outras existem. Invisibilizadas pela falácia do monoglotismo, estão não apenas as línguas de inclusão, como a Libras (Língua Brasileira de Sinais, usada pela comunidade surda), como também as línguas orais das diversas comunidades de imigrantes e também as dos povos originários.

Apesar de cinco séculos de esforços para acabar física e culturalmente com os/as remanescentes indígenas, eles/as não apenas seguem existindo de acordo com o IBGE (2012), como, inclusive, voltaram a se reconhecer como tal. Um dos dados mais significativos revelados pelo Censo de 2000 (IBGE, 2012, p. 8) é o fenômeno da etnogênese (ou reetnização):

[...] mesmo havendo evidências de que a população indígena estivesse experimentando acelerado crescimento [...] os dados censitários de 2000 superaram todas as expectativas, com um ritmo de crescimento anual, no período 1991/2000, da ordem de 10,8\%. Portanto, as alterações nas composições absoluta e relativa verificadas de 1991 para 2000 são reflexo do crescimento do número de pessoas que, no Censo Demográfico 1991, se identificaram como de outras categorias e, em 2000, passaram a se identificar como indígenas. 
Também, as línguas indígenas seguem existindo e conservando narrativas, história e cultura destes povos originários. Embora não estejam mais na proporção das muitas centenas, como referido por Wyler (2013), os números são significativos: os resultados do Censo 2010 apontaram 274 línguas indígenas faladas por pessoas pertencentes a 305 etnias diferentes (conforme matéria de ABDALA (2014) para a EBC. Cinco línguas indígenas teriam mais de dez mil falantes no Brasil em 2010: o tikuna (com 34 mil falantes), o guarani kaiowá (com 26,5 mil), o kaigang (22 mil), o xavante (13,3 mil) e o yanomami (12,7 mil). Trata-se de uma pequena Babel que resiste bravamente a opressões e dominações várias, neste caso, as do plano linguístico.

Por certo, são muitos os desafios na questão indígena do Brasil, mas esses dois dados, sobre a reetnização e a resistência das línguas indígenas, parecem boas notícias em meio ao quadro traçado por este trabalho, e espera-se que o retrato do Brasil a ser empreendido pelo Censo de 2020 confirme essas resistências linguísticas e demais elementos que constituem os direitos culturais indígenas.

No entanto, a abertura para um processo realmente democrático passa, necessariamente, pelo reconhecimento do multilinguismo e da participação dos povos originários nos rumos da nação, o que perpassa a ideia de interculturalidade, ou seja, dos "processos de construção de um conhecimento outro, de uma outra prática política, de um outro poder social (e estatal) e de outras sociedades; uma outra forma de pensamento relacionada com e contra a modernidade/colonialidade e um outro paradigma que é pensado através da práxis política" (WALSH, 2007, p. 47) que envolve a representação política das diversas identidades de uma nação.

Nesse sentir, quando a Constituição Brasileira de 1988 consolida, em apenas dois artigos ${ }^{21} \mathrm{o}$ direito de mulheres e homens indígenas seguirem sendo indígenas (SOUSA FILHO, 2013, p. 17), tem-se, em verdade, a instituição deliberada do chamado multiculturalismo oficial, nada afeito à interculturalidade, que pressupõe, entre outras coisas, sua participação nas tomadas de decisão de um Estado.

Assim, apesar de, no plano teórico, assegurar-se a existência e salvaguarda da cultura indígena, endossando a coexistência de uma ordem legal interna sujeita aos usos e costumes, línguas, crenças e tradições próprias

21 Art. 231. São reconhecidos aos índios sua organização social, costumes, línguas, crenças e tradições, e os direitos originários sobre as terras que tradicionalmente ocupam, competindo à União demarcálas, proteger e fazer respeitar todos os seus bens. [...] e Art. 232. Os índios, suas comunidades e organizações são partes legítimas para ingressar em juízo em defesa de seus direitos e interesses, intervindo o Ministério Público em todos os atos do processo. 
(SOUSA FILHO, 2013), este suposto avanço pouco tem respeitado a cultura indígena no permitir que coabite com a forma hegemônica. Do contrário, apenas simula este "novo" pensar a fim de que se mantenham intactas as mesmas estruturas de poder. Nota-se que,

É nessa nova fase multiculturalista de se pensar a questão do "outro", que temos a chegada do índio permitido à esfera pública. Representa um novo cenário no qual se aceitam as demandas culturais sempre que não impliquem uma redistribuição real dos recursos e do poder, tampouco questionamento das relações de saber (COLAÇO; DAMÁSIO, 2012, p. 104).

Mesmo nos países em que a interculturalidade tenha sido um pouco mais concreta, a exemplo do Equador e da Bolívia, onde o projeto político do Buen Vivir ou Sumak Kawsay foi constitucionalmente implementado, tem-se entraves. Nos moldes constitucionais, esta deveria ser uma possibilidade "para construir outra sociedade, sustentada em uma convivência cidadã em diversidade e harmonia com a Natureza, a partir do conhecimento dos diversos povos culturais existentes no país e no mundo" (ACOSTA 2016, p. 76). No entanto, o que era para ser um projeto integrador de diversos povos e nacionalidades indígenas, em que as suas singularidades fossem respeitadas, incluídas, emancipadas e ouvidas, o que se vislumbra é que os povos originários têm sido consideravelmente afetados pelas políticas voltadas ao modelo desenvolvimentista de sociedade global (cabe mencionar aqui a destituição de Evo Morales da presidência da Bolívia, ocorrida em 2019).

Isso informa que a mera consolidação de dispositivos constitucionais protetores dos direitos indígenas não significa a sua efetividade e, muito menos, importará que esses direitos sejam resguardados das influências do processo hegemônico civilizatório, do sistema-mundo europeu ou euro-estadunidense, capitalista/patriarcal, moderno/colonial.

Em verdade, grande parte dos atos que desguarnecem os povos indígenas de sua originalidade é uma violência. Para Spivak, subsiste a preocupação com a constituição de um sujeito ético em relação à língua que usa:

\footnotetext{
Às vezes leio e ouço que o subalterno pode falar em suas línguas nativas. Eu gostaria de poder ter essa autoconfiança tão firme e inabalável que têm o intelectual, o crítico literário e o historiador que, aliás, afirmam isso em inglês. Nenhuma fala é fala enquanto não é ouvida (SPIVAK, 2005, p. 57-58).
}

Nesse sentido, Spivak pressupõe a existência de pessoas atentas e dispostas a ouvir as pessoas subalternizadas para, em nome delas, responder 
- eis o imperativo ético da reflexão sobre a fala; implica a participação dos subalternizados nas tomadas de decisão de um Estado. Foi visando à reconstrução da identidade desse sujeito indígena subalternizado e de, em nome dele falar (para que a sua fala seja ouvida), que se trouxe o aspecto linguístico no processo de colonização do Brasil. Afinal, a discriminação aos idiomas indígenas nesse processo, na esteira de Santos (2010, p. 38), envolve reconhecer a violência na proibição do uso de suas línguas e de seus nomes próprios, e bem assim de seus cultos e de sua perspectiva de educação, arte e justiça constituídas e disseminadas pelas línguas que usam. Em suma, de sua cultura. Mas, também, envolve reconhecer a persistência e, em boa parte, a vitória no apagamento da cultura indígena brasileira e sobretudo a resistência destes povos originários na conservação de seus direitos culturais e linguísticos.

De igual modo, é negar a multiculturalidade da nação ao submeter o Brasil à "hegemonia das oligarquias agroexportadoras ligadas aos interesses externos e adeptas do individualismo liberal, do elitismo colonizador e da legalidade lógico-formal" (WOLKMER, 2001, p. 84).

Assim, o percurso histórico proposto neste trabalho demonstrou que, em 1500, os colonizadores portugueses encontraram um Brasil plurilíngue, com redes comunicantes de contato a empregar línguas francas tão efetivas e tão amplamente difundidas, que a chamada "língua geral", que perdurou até o século XIX, era de base tupi (herdeira do nheengatu). Em 1900, o Brasil republicano dominante seguiria sendo essencialmente oral, porque majoritariamente analfabeto, mas mesmo assim estruturado numa "consciência" coletiva construída com base na suposta inferioridade da cultura e dos saberes indígenas e superioridade do pensamento colonizador.

Necessário, pois, a desconstrução desses e de todos os mitos para que, livres das correntes abissais, seja possível promover um real e efetivo processo de decolonialidade política, econômica, cultural, linguística e também teórica, razão pela qual a teoria decolonial encontra acolhida neste trabalho que clama, ademais, pela construção de uma teoria decolonial à brasileira para fazer frente à interpretação das peculiaridades das diferentes opressões coloniais no Brasil.

\section{CONCLUSÃO}

Este trabalho partiu de pesquisa de história e historiografia da cultura, das línguas e das formas de disseminação de saberes no Brasil para traçar 
uma análise da insistência do pensamento colonial, ao mesmo passo que apresentou peculiaridades do colonialismo brasileiro que, em oposição ao da América Espanhola, proibiu a circulação de material impresso e a criação de universidades até 1808, quando se deu a chegada da Corte de Dom João VI ao Rio de Janeiro.

Da mesma forma, mostrou-se como, até 1759, a educação esteve em mãos dos jesuítas com o fim exclusivo de formação de missionários e que as heranças deste período são ainda sentidas na contemporaneidade, marcada por uma educação de cunho patriarcal, excludente e pouco cientificista. A ruptura com esse modelo por meio das reformas pombalinas, como é frequente na história brasileira, trouxe diversos prejuízos, perseguições e destruições, sem conseguir implementar um sistema educacional laico e democrático. Inaugurada já a terceira década do século XXI, lamentavelmente se pode concluir que esse desafio ainda está longe de ser concretizado e que talvez não o será enquanto perdurarem as amarras do pensamento colonial.

Assim, em que pese a dominação ter-se calcado sobre a crença de que modernidade e racionalidade são patrimônios exclusivos dos europeus, procurou-se demonstrar que, no Brasil, as ditas "elites" dirigentes, não são nem modernas nem muito menos racionais, e que mantiveram-se a si mesmas e à maioria do país majoritariamente mergulhada no analfabetismo de massa, que, até meados do século XX, relegou mais da metade da população brasileira à margem não apenas do mais básico dos letramentos, mas também (e consequência do primeiro elemento) do mais básico dos exercícios de cidadania, o direito ao voto. Nesse contexto pouco propício à ascensão social por meio de estudos, o gênero, a cor da pele, o ofício realizado e o ter (terras, dinheiro ou apadrinhamento) seguiram sendo os mecanismos conferidores de prestígio nesse país em que aliançar-se (apadrinhar-se) com os/as opressores/as forjou-se, para muitos homens e mulheres, como a única ou principal opção em face da ausência ou insuficiência de proteção por parte do Estado. A partir disso, demonstrou-se como a sobreposição de dominações impediu a integração social e manteve parcelas da população sempre subjugadas a outras, como inimigas entre si.

Evidenciou-se, também, que a simples consagração de dispositivos constitucionais que intentem assegurar a multiculturalidade existente no Brasil não é suficiente para garantir a coexistência com o modelo hegemônico, em que pesem indicadores da resistência indígena retratados na etnogênese e na diversidade de línguas indígenas ainda faladas. 
Do contrário, apenas quando se apreciar a promoção definitiva do reconhecimento do multilinguismo, expresso nos direitos linguísticos, e da participação dos povos originários na tomada de decisões estatais (interculturalidade) é que estes povos poderão ter perspectivas de efetivação dos direitos culturais e linguísticos.

Por fim, o (re)conhecimento e avivamento do passado, da cultura, das características demográficas e linguísticas e das peculiaridades do processo de colonização brasileiro conduz à constatação da urgência de uma epistemologia genuinamente decolonial, que busque reconhecer-se como brasileira, em diálogo com a latino-americana naquilo que une a todos estes povos, que acolha as diferenças e os pensamentos outros e anule os contínuos esforços de apagamento da cultura indígena frente sua marcada resistência para conservar o código que melhor expressa as ideias, os pensamentos e que constitui a cultura de um povo, ou seja, a língua, o direito de se expressar na sua própria língua.

\section{REFERÊNCIAS}

ABDALA, V. Brasil tem cinco línguas indígenas com mais de 10 mil falantes. $E B C, 11$ dez. 2014 e Disponível em: http://www.ebc.com.br/cultura/2014/12/brasil-tem-cinco-linguas-indigenas-com-mais-de-10-mil-falantes. Acesso em: 16 jul. 2019.

ACOSTA, A. O bem viver: uma oportunidade para imaginar outros mundos. São Paulo: Autonomia Literária, 2016.

ALMEIDA, J. D. L. História do Brasil. Brasília, DF: Funag, 2013.

AVELAR, L.; CINTRA, A. O. Sistema político brasileiro: uma introdução. 2. ed.rev. ampl. Rio de Janeiro: Konrad-Adenauer-Stifung; São Paulo: Unesp, 2007. p. 19-34.

BOSI, A. História concisa da literatura brasileira. 43. ed. São Paulo: Cultrix, 2006.

CANDIDO, A. Literatura e subdesenvolvimento. In: CANDIDO, A. A educação pela noite e outros ensaios. São Paulo: Ática, 1989. p. 140-162.

CARVAlHO, J. M. Cidadania no Brasil: o longo caminho. 3. ed. Rio de Janeiro: Civilização Brasileira, 2002.

CARVALHO, J. M. Fundamentos da política e da sociedade brasileiras. 
In: COLAÇO, T. L.; DAMÁSIO, E. S. P. Novas perspectivas para a antropologia jurídica na América Latina: o direito e o pensamento decolonial. Florianópolis: Fundação Boiteux, 2012.

GARCÉS, F. Las políticas del conocimiento y la colonialidad lingüística y epistémica. In: CASTRO-GÓMEZ, S.; GROSFOGUEL, R. (orgs.). El giro decolonial: reflexiones para una diversidad epistémica más allá del capitalismo global. Bogotá: Siglo del Hombre, 2007.

GROSFOGUEL, R. The implications of subaltern epistemologies for global capitalism: transmodernity, border thinking and global coloniality. In: APPELBAUM, R. P.; ROBINSON, W. I. (eds.). Critical globalization. New York/London: Routledge, 2005.

HALLEWELL, L. O livro no Brasil: sua história. 3. ed. São Paulo: Edusp, 2012.

HOUAISS, A. Dicionário Eletrônico Houaiss da Língua Portuguesa versão 3.0. rev., ampl. atual. São Paulo: Objetiva, 2009. 1 CD-ROM.

IBGE - INSTITUTO BRASILEIRO DE GEOGRAFIA E ESTATÍSTICA. PNAD Contínua 2018: $10 \%$ da população concentram 43,1\% da massa de rendimentos do país. Agência de Notícias, 16 out. 2019. Disponível em: https://agenciadenoticias.ibge.gov.br/agencia-sala-de-imprensa/2013-agencia-de-noticias/releases/25700-pnad-continua-2018-10-da-populacao-concentram-43-1-da-massa-de-rendimentos-do-pais. Acesso em: $19 \mathrm{dez}$. 2019 .

IBGE - INSTITUTO BRASILEIRO DE GEOGRAFIA E ESTATÍSTICA. Anuário Estatístico do Brasil. v. 74. Rio de Janeiro: IBGE, 2014. Disponível em: http://biblioteca.ibge.gov.br/visualizacao/periodicos/20/aeb_2014. pdf. Acesso em: 2 de nov. 2019.

IBGE - INSTITUTO BRASILEIRO DE GEOGRAFIA E ESTATÍSTICA. Os indígenas no Censo demográfico 2010: primeiras considerações com base no quesito cor ou raça. Rio de Janeiro: IBGE, 2012. Disponível em: https://ww2.ibge.gov.br/indigenas/indigena_censo2010.pdf. Acesso em: 8 jul. 2019.

IBGE - INSTITUTO BRASILEIRO DE GEOGRAFIA E ESTATÍSTICA. Tendências demográficas no período 1950 a 2000: uma análise dos resultados da amostra do Censo demográfico 2000. Rio de Janeiro: IBGE, 
2010. Disponível em: http://www.ibge.gov.br/home/estatistica/populacao/ censo2000/tendencias_demograficas/comentarios.pdf. Acesso em: 6 dez. 2019.

KAHMANN, A. P. Perspectivismo, corazonar e estar: educação e sabedorias xamânicas no Santo Daime. Dissertação (Mestrado em Educação) - Universidade de Santa Cruz do Sul, Santa Cruz do Sul, 2017.

KHATIBI, A. Maghreb pluriel. Paris: Denoel, 1983.

MERCOSUL. Comissão Permanente de Gênero e Direito das Mulheres da Reunião de Altas Autoridades em Direitos Humanos e Chancelaria do MERCOSUL (RAADH). Manual pedagógico sobre el uso del lenguaje inclusivo y no sexista. Buenos Aires, IPPDH, 2018. 28p. Disponível em: http://www.ippdh.mercosur.int/pt-br/publicaciones/manual-pedagogico-sobre-o-uso-da-linguagem-inclusiva-nao-sexista/. Acesso em: 15 fev. 2019.

MIGNOLO, W. Os esplendores e as misérias da 'ciência': colonialidade, geopolítica do conhecimento e pluri-versalidade epistémica. In: SANTOS, B. S. (ed.). Conhecimento prudente para uma vida decente: um discurso sobre as 'ciências' revistado. Lisboa: Afrontamento, 2003.

QUIJANO, A. Colonialidad del poder, eurocentrismo y America Latina. In: LANGER, E. (Org.) La colonialidad del saber: eurocentrismo y ciencias sociales. Buenos Aires: CLACSO, 2005. p. 201-246.

. Bienvivir: entre el desarrollo y la des/colonialidad del poder. In: QUIJANO, A. (ed.). Des/colonialidad y bien vivir: un nuevo debate en América Latina. Lima: Editorial Universitaria, 2014. Disponível em: http://www.mapuche.info/wps_pdf/quijano\%202014.pdf. Acesso em: 24 jun. 2019.

. Colonialidad del poder y clasificación social. In: CASTRO-GÓMEZ, S.; GROSFOGUEL, R. (orgs.). El giro decolonial: refl exiones para una diversidad epistémica más allá del capitalismo global. Bogotá: Siglo del Hombre, 2007.

SACHS, I. Desenvolvimento includente, sustentável e sustentado. Rio de Janeiro: Garamond, 2008.

SANTOS, B. S. Para além do pensamento abissal: das linhas globais a uma ecologia de saberes. In: SANTOS, B. S; MENESES, M. P. (Orgs.). Epistemologias do sul. São Paulo: Cortez, 2010. p. 31-83. 
SILVA, N. V.; BARBOSA, L. O. População e estatísticas vitais. In: IBGE - INSTITUTO BRASILEIRO DE GEOGRAFIA E ESTATÍSTICA. Estatísticas do século XX. Rio de Janeiro: IBGE, 2006. Disponível em: http:// seculoxx.ibge.gov.br/images/seculoxx/seculoxx.pdf. Acesso em: 2 nov. 2019.

SOUSA FILHO, C. F. M.; BERGOLD, R. C. (Orgs). Os direitos dos povos indígenas no Brasil: desafios no século XXI. Curitiba: Letra da Lei, 2013. SPIVAK, G. C. Tradução como cultura. Ilha do Desterro, Florianópolis, n. 48, p. 41-64, jan./jun. 2005.

TORRES, M. H. C. Best-sellers em tradução: o substrato cultural internacional. Alea, Rio de Janeiro, v. 11, n. 2, dez. 2009. Disponível em: http://www.scielo.br/scielo.php?script=sci_arttext\&pid=S1517-106X2009000200006. Acesso em: 30 out. 2019.

WALSH, C. (Re)Pensamiento crítico e (de) colonialidad. In: WALSH, C. Pensamiento crítico y matriz (de)colonial: reflexiones latinoamericanas. Quito: Universidad Andina Simón Bolívar; Abya-Yala, 2005.

. Interculturalidad y colonialidad del poder: un pensamiento y posicionamiento "otro" desde la diferencia colonial. In: CASTRO-GÓMEZ, S.; GROSFOGUEL, R. (orgs.). El giro decolonial: reflexiones para una diversidad epistémica más allá del capitalismo global. Bogotá: Siglo del Hombre, 2007.

WOLKMER, A. C. Pluralismo jurídico: fundamentos de uma nova cultura do direito. 4. ed. São Paulo: Saraiva, 2001. Disponível em: http://www. forumjustica.com.br/wp-content/uploads/2013/02/Antonio-CarlosWolkmer-Pluralismo-juridico.pdf. Acesso em: 30 out. 2019.

WYLER, L. Lingua, poetas e bacharéis: uma crônica da tradução no Brasil. Rio de Janeiro: Rocco, 2003.

Artigo recebido em: 07/11/2019.

Artigo aceito em: 04/03/2020. 


\section{Como citar este artigo (ABNT):}

KAHMANN, A. C.; BERTOLDI, M. R.; FIGUEROA, I. Línguas, livros e leis: o apagamento da cultura indígena e resistência. Veredas do Direito, Belo Horizonte, v. 17, n. 37, p. 61-87, jan.-abr. 2020. Disponível em: http:// revista.domhelder.edu.br/index.php/veredas/article/view/1703. Acesso em: dia mês. ano. 